\title{
A New Scoring-system for Estimating Overall Survival After Radiotherapy of Recurrent Head and Neck Cancers
}

\author{
DIRK RADES ${ }^{1}$, DANIEL SEIDL ${ }^{1}$, STEFAN JANSSEN ${ }^{1,2}$, SAMER G. HAKIM ${ }^{3}$, \\ BARBARA WOLLENBERG ${ }^{4}$, TOBIAS BARTSCHT ${ }^{5}$ and STEVEN E. SCHILD ${ }^{6}$ \\ Departments of ${ }^{1}$ Radiation Oncology, ${ }^{3}$ Oral and Maxillofacial Surgery, \\ ${ }^{4}$ Oto-Rhino-Laryngology and Head and Neck Surgery, \\ and ${ }^{5}$ Hematology and Medical Oncology, University of Lübeck, Lübeck, Germany; \\ ${ }^{2}$ Medical Practice for Radiotherapy and Radiation Oncology, Hannover, Germany; \\ ${ }^{6}$ Department of Radiation Oncology, Mayo Clinic, Scottsdale, AZ, U.S.A.
}

\begin{abstract}
Background/Aim: Locoregional recurrences of head and neck cancers are often associated with a poor overall survival (OS). Outcomes may be improved with individualized treatments considering a patient's lifespan. A specific scoring system for estimating OS prognoses is presented. Patients and Methods: In a preceding study of these 60 patients, Eastern Cooperative Oncology Group performance score (ECOG 0-1 versus 2, $p=0.002$ ) and $N$-stage (NO-1 versus $N 2, p=0.004)$ were identified as independent predictors of OS. Results: In the current study, the following scoring points were assigned: ECOG performance score $2=0$ points, ECOG performance score 0 $1=1$ point, $N 2=0$ points, $N O-1=1$ point. Patient scores were 0,1 or 2 points with 3 -year OS rates of $0 \%, 46 \%$ and $83 \%$, respectively $(p<0.0001)$. On multivariable analysis, differences remained significant $(p<0.0001)$. Conclusion: This new scoring system includes three groups of patients with significantly different OS prognoses and can assist physicians when designing individualized therapy for locoregional recurrences of head and neck cancer.
\end{abstract}

Locoregional recurrence is quite common in patients treated for head and neck cancer and is often associated with a poor overall survival (OS) $(1,2)$. In addition to modern technology including intensity-modulated radiotherapy (IMRT) or volumetric-modulated arc therapy (VMAT), the outcomes of these patients may be improved with the

Correspondence to: Professor Dirk Rades, MD, Department of Radiation Oncology, University of Lübeck, Ratzeburger Allee 160, 23562 Lübeck, Germany. Tel: +49 45150045400, Fax: +49 45150045404, e-mail: rades.dirk@gmx.net

Key Words: Scoring system, overall survival, head and neck cancer, locoregional recurrence, radiotherapy. administration of individualized treatment approaches. Individualized therapy should account for the patient's personal preference, social situation, age, co-morbidity index, and remaining lifespan. In patients with short expected OS, short and less burdensome treatment should be preferred, whereas in patients with a comparably long remaining lifetime, long-term locoregional control and reduction of the risk of developing late treatment-related morbidity are more important (3-7). These considerations lead to the conclusion that it is important to be able to estimate an individual patient's OS time. In a previous study, we identified independent predictors of OS in a series of patients irradiated for a locoregional recurrence of head and neck cancer (8). However, a specific scoring system would be more convenient and easier to use during daily clinical care. Therefore, the current study was conducted to create a specific scoring system to estimate the survival of patients irradiated for locally recurrent head and neck cancer.

\section{Patients and Methods}

A total of 60 patients were irradiated for locoregional recurrence of squamous cell carcinoma in the head and neck region and included in this retrospective analysis. In a preceding study, 12 potential prognostic factors were investigated for a potential impact on OS following radiotherapy. These factors were age, gender, primary tumor site, initial tumor stage, type of primary treatment, time from first diagnosis of the head and neck tumor until the beginning of radiation therapy for the recurrence, performance status, T-stage of the recurrence, $\mathrm{N}$-stage of the recurrence, upfront surgery, simultaneous chemotherapy and the total dose of radiotherapy. Of these variables, the Eastern Cooperative Oncology Group performance score (ECOG 0-1 versus $\mathrm{ECOG} 2$; hazard ratio=3.69; $p=0.002$ ) and $\mathrm{N}$-stage (N0-1 versus $\mathrm{N} 2$; hazard ratio=3.20; $p=0.004$ ) were significantly (defined as $p<0.05$ ) associated with OS on multivariable analysis in our previous publication (8). Therefore, both ECOG performance score and $\mathrm{N}$-stage were included in the scoring system created in the present study. 


\section{Results}

Median follow-up times were 17.5 months (range: 1-96 months) for the entire cohort and 36 months (range: 6-96 months) for those patients who were still alive at their last follow-up. The following points were assigned to the variables: ECOG performance score $2=0$ points, ECOG performance score $0-1=1$ point, $\mathrm{N} 2=0$ points, $\mathrm{N} 0-1=1$ point. The points were summed for individual patients and were 0 , 1 or 2 points. The OS rates at 1,2 and 3 years associated with the different scores are summarized in Table I. The three possible scores were compared for OS using the Kaplan-Meier method supplemented by the log-rank test (Figure 1), which demonstrated that the difference between the three total scores was significant $(p<0.0001)$. The median OS times were 5 months, 26 months and >39 months (median not reached), respectively. The total score was an independent predictor of OS as confirmed by multivariate analysis using the Cox proportional hazards model. Indeed, the impact of the total score on OS remained significant (hazard ratio=3.35, 95\%-confidence interval=1.89-6.02, $p<0.0001)$.

\section{Discussion}

The outcomes of patients with loco-regional recurrences of head and neck cancer are poor and may be improved with the strategy of personalized treatment (9). As in other oncological situations, a patient's expected OS is an important consideration when choosing the best treatment regimen (3-7). In a previous study of 60 patients receiving radiotherapy for locoregional recurrence of head and neck cancer, we identified two independent prognostic factors independently associated with OS (8). Such prognostic factors play an important role when physicians tailor their treatment regimen to a specific individual. In order to facilitate personalized care, we created a scoring system from that cohort that allows estimation of the OS prognosis of patients. This scoring system was based on the two previously identified independent prognostic factors, namely ECOG performance score and $\mathrm{N}$-stage at recurrence (8). Three prognostic groups were identified, i.e. those with 0 points, 1 point and 2 points. According to the results of the present study, these groups were associated with significantly different OS prognoses (Table I).

In the group with 0 points, only $18 \%$ of the patients survived for 1 year following radiotherapy, and the median OS time was only 5 months. Therefore, these patients may be considered as requiring palliative therapy and should probably receive a radiation regimen that is not aggressive or burdensome. Furthermore, the overall treatment time should be kept as short as possible. Shorter hypofractionated regimens such as $13 \times 3$ Gy in 2.5 weeks or $18 \times 2.5$ Gy in 3.5

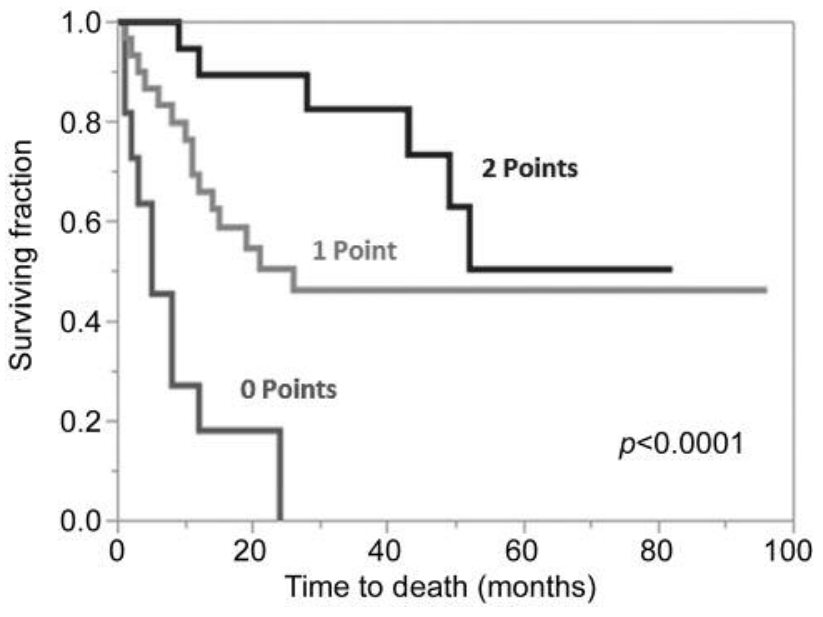

Figure 1. Kaplan-Meier curves of the three prognostic groups $(0,1$ and 2 points) for overall survival (OS). The p-value was calculated with the log-rank test.

Table I. Overall survival (OS) following radiotherapy of a locoregional recurrence of head and neck cancer.

\begin{tabular}{lcccc}
\hline & \multicolumn{4}{c}{ OS $(\%)$} \\
\cline { 2 - 4 } Total score & At 1 year & At 2 years & At 3 years & $p$-Value \\
\hline 0 Points $(\mathrm{N}=11)$ & 18 & 0 & 0 & \\
1 Point $(\mathrm{N}=30)$ & 66 & 50 & 46 & \\
2 Points $(\mathrm{N}=19)$ & 89 & 89 & 83 & $<0.0001$ \\
\hline
\end{tabular}

weeks may be more appropriate options than conventionally fractionated radiotherapy with 2-Gy fractions up to 60-70 Gy over 6 to 7 weeks. Patients of the group with 1 point had an intermediate OS prognosis, with $50 \%$ surviving for at least 2 years following radiotherapy and a median OS time of 26 months. Therefore, these patients may not be ideal candidates for a palliative approach with hypofractionated radiotherapy and should receive conventional radiotherapy over 6-7 weeks instead. If complete resection is not performed or patients with head and neck cancer have an extracapsular extension of lymph node metastases, radiotherapy should be administered with concurrent chemotherapy. If no contraindications exist, chemotherapy should be cisplatin-based (10-13). Other options of systemic therapies include carboplatin, mitomycin $\mathrm{C}$ plus 5fluorouracil, cetuximab or paclitaxel (11, 14-16). Those patients who achieved 2 points had the most favorable OS prognoses, with a 3 -year OS rate of $83 \%$. Patients within this group would likely benefit from the same recommendations as the group with 1 point. However, because the risk of 
radiation-related late morbidity increases over time, treatment for these more favorable patients in the group with 2 points should include greater efforts at sparing of normal tissues such as parotid glands, larynx, swallowing muscles and others in order to prevent late toxicity. Therefore, these patients should be irradiated with modern techniques such as IMRT and VMAT. When interpreting these results, one should bear in mind that the scoring system was developed from retrospective data. Therefore, inclusion of a hidden selection bias might exist.

In summary, this new scoring system divides patients irradiated for recurrent head and neck malignancies into three groups with significantly different OS prognoses. This score provides a helpful tool to assist physicians in estimating survival and choosing an individualized treatment approach for patients with locoregional recurrence of head and neck cancer. It could also be used for patient stratification in future trials designed for patients with recurrent disease.

\section{Conflicts of interest}

On behalf of all Authors, the corresponding Author states that there is no conflict of interest related to this study.

\section{References}

1 Bernier J, Domenge C, Ozsahin M, Matuszewska K, Lefèbvre JL, Greiner RH, Giralt J, Maingon P, Rolland F, Bolla M, Cognetti F, Bourhis J, Kirkpatrick A and van Glabbeke M; European Organization for Research and Treatment of Cancer Trial 22931: Postoperative irradiation with or without concomitant chemotherapy for locally advanced head and neck cancer. N Engl J Med 350: 1945-1952, 2004.

2 Cooper JS, Pajak TF, Forastiere AA, Jacobs J, Campbell BH, Saxman SB, Kish JA, Kim HE, Cmelak AJ, Rotman M, Machtay M, Ensley JF, Chao KS, Schultz CJ, Lee N, Fu KK and Radiation Therapy Oncology Group 9501/Intergroup: Postoperative concurrent radiotherapy and chemotherapy for high-risk squamous-cell carcinoma of the head and neck. N Engl J Med 350: 1937-1944, 2004.

3 Rades D, Douglas S, Veninga T, Stalpers LJ, Hoskin PJ, Bajrovic A, Adamietz IA, Basic H, Dunst J and Schild SE: Validation and simplification of a score predicting survival in patients irradiated for metastatic spinal cord compression. Cancer 116: 3670-3673, 2010.

4 Rades D, Hueppe M and Schild SE: A score to identify patients with metastatic spinal cord compression who may be candidates for best supportive care. Cancer 119: 897-903, 2013.

5 Rades D, Dziggel L, Nagy V, Segedin B, Lohynska R, Veninga T, Khoa MT, Trang NT and Schild SE: A new survival score for patients with brain metastases who received whole-brain radiotherapy (WBRT) alone. Radiother Oncol 108: 123-127, 2013.

6 Dziggel L, Segedin B, Podvrsnik NH, Oblak I, Schild SE and Rades D: Validation of a survival score for patients treated with whole-brain radiotherapy for brain metastases. Strahlenther Onkol 189: 364-366, 2013.
7 Rades D, Käsmann L, Schild SE and Janssen S: A survival score for patients receiving palliative irradiation for locally advanced lung cancer. Clin Lung Cancer 17: 558-562, 2016.

8 Seidl D, Schild SE, Wollenberg B, Hakim SG and Rades D: Prognostic factors in patients irradiated for recurrent head-andneck cancer. Anticancer Res 36: 6547-6550, 2016.

9 Yamazaki H, Demizu Y, Okimoto T, Ogita M, Himei K, Nakamura S, Suzuki G, Yoshida K, Kotsuma T and Yoshioka Y: Comparison of re-irradiation outcomes for charged particle radiotherapy and robotic stereotactic radiotherapy using CyberKnife for recurrent head and neck cancers: A multiinstitutional matched-cohort analysis. Anticancer Res 36: 5507$5514,2016$.

10 Rades D, Seidl D, Janssen S, Bajrovic A, Hakim SG, Wollenberg $\mathrm{B}$ and Schild SE: Do we need 5-FU in addition to cisplatin for chemoradiation of locally advanced head-and-neck cancer? Oral Oncol 57: 40-45, 2016.

11 Rades D, Ulbricht T, Hakim SG and Schild SE: Cisplatin superior to carboplatin in adjuvant radiochemotherapy for locally advanced cancers of the oropharynx and oral cavity. Strahlenther Onkol 188: 42-48, 2012.

12 Rades D, Seidl D, Janssen S, Bajrovic A, Hakim SG, Wollenberg B, Karner K, Strojan P and Schild SE: Chemoradiation of locally advanced squamous cell carcinoma of the head-and-neck (LASCCHN): Is $20 \mathrm{mg} / \mathrm{m}$ (2) cisplatin on five days every four weeks an alternative to $100 \mathrm{mg} / \mathrm{m}(2)$ cisplatin every three weeks? Oral Oncol 59: 67-72, 2016.

13 Rades D, Seidl D, Janssen S, Strojan P, Karner K, Bajrovic A, Hakim SG, Wollenberg B and Schild SE: Comparing two lowerdose cisplatin programs for radio-chemotherapy of locally advanced head-and-neck cancers. Eur Arch Otorhinolaryngol 274: 1021-1027, 2017.

14 Budach V, Stuschke M, Budach W, Baumann M, Geismar D, Grabenbauer G, Lammert I, Jahnke K, Stueben G, Herrmann T, Bamberg M, Wust P, Hinkelbein $\mathrm{W}$ and Wernecke KD: Hyperfractionated accelerated chemoradiation with concurrent fluorouracil-mitomycin is more effective than dose-escalated hyperfractionated accelerated radiation therapy alone in locally advanced head and neck cancer: final results of the radiotherapy cooperative clinical trials group of the German Cancer Society 95-06 Prospective Randomized Trial. J Clin Oncol 23: 1125$1135,2005$.

15 Rades D, Seidl D, Wollenberg B, Schild SE and Hakim SG: Radiochemotherapy with paclitaxel for recurrent previously irradiated squamous cell carcinoma of the head and neck. Anticancer Res 36: 5463-5468, 2016.

16 Bonner JA, Harari PM, Giralt J, Cohen RB, Jones CU, Sur RK, Raben D, Baselga J, Spencer SA, Zhu J, Youssoufian H, Rowinsky EK, Ang KK: Radiotherapy plus cetuximab for locoregionally advanced head and neck cancer: 5-year survival data from a phase 3 randomised trial, and relation between cetuximab-induced rash and survival. Lancet Oncol 11: 21-28, 2010 .

Received December 4, 2017

Revised January 4, 2018

Accepted January 10, 2018 